\title{
The Infectious Aspects of Atopic Dermatitis
}

\author{
Peck Y. Ong, $\mathbf{M D}^{1,2}$ and Donald Y. M. Leung, MD, PhD $^{3,4,5}$ \\ ${ }^{1}$ Division of Clinical Immunology and Allergy, Children's Hospital Los Angeles, Los Angeles, CA, \\ USA \\ ${ }^{2}$ Department of Pediatrics, University of Southern California Keck School of Medicine, Los \\ Angeles, CA, USA \\ ${ }^{3}$ Division of Pediatric Allergy-Immunology, National Jewish Health, Denver, CO, USA \\ ${ }^{4}$ Department of Pediatrics, University of Colorado Denver, Denver, CO, USA.
}

\section{Synopsis}

\begin{abstract}
Atopic dermatitis is characterized by S. aureus colonization and recurrent skin infections. In addition to an increased risk of invasive infections by herpes simplex or vaccinia viruses, there is ample evidence that microbial pathogens, particularly $S$. aureus and fungi, contribute to the cutaneous inflammation of atopic dermatitis. We describe recent developments in the pathogenesis of atopic dermatitis in relation to the role of microbial pathogens. Understanding how microbial pathogens interact or evade the cutaneous immunity of atopic dermatitis may be crucial in preventing infections or cutaneous inflammation in this disease.
\end{abstract}

\section{Introduction}

Atopic dermatitis (AD) is a chronic inflammatory skin disease that causes significant morbidity in affected individuals. The disease is often characterized by chronic inflammation and pruritus interrupted by acute flares and bacterial infection [1]. It results in significant sleep loss, poor school/work performance and disruption of social activities. In addition, severe $\mathrm{AD}$ patients are at risk for rare invasive bacterial infections and lifethreatening eczema herpeticum [2,3]. Although recent studies have provided strong support for the basis of skin barrier defects in the pathogenesis of $\mathrm{AD}$ [4], the cause of $\mathrm{AD}$ remains incompletely understood. More recent data have also provided further insights into the important role of immune responses in the pathogenesis of $\mathrm{AD}$ (Table 1). Of note, $\mathrm{AD}$ patients with increased allergic responses have more severe skin disease as well as a greater tendency to suffer from skin infections. These studies provide evidence for a role of the immune response in the expression of AD. Secondary skin infections have long been known to be associated with $\mathrm{AD}$ flare. The most common skin infections in $\mathrm{AD}$ are caused by Staphylococcus aureus (S. aureus) and herpes simplex virus (HSV). In the absence of clinical signs of infections, the majority of AD patients are also colonized with S. aureus on

(C) 2010 Elsevier Inc. All rights reserved.

${ }^{5}$ Corresponding author: Donald Y. M. Leung, MD, PhD, National Jewish Health, 1400 Jackson St, Denver, CO 80206 USA, Tel: 303-398-1379, Fax: 303-270-2182, leungd@ njhealth.org.

Co-author: Peck Y. Ong MD, University of Southern California, Keck School of Medicine, Los Angeles, CA, USA, Tel: 323-361-2501, Fax: pyong@chla.usc.edu

Publisher's Disclaimer: This is a PDF file of an unedited manuscript that has been accepted for publication. As a service to our customers we are providing this early version of the manuscript. The manuscript will undergo copyediting, typesetting, and review of the resulting proof before it is published in its final citable form. Please note that during the production process errors may be discovered which could affect the content, and all legal disclaimers that apply to the journal pertain. 
their skin lesions. This pathogen is known to produce a myriad of pro-inflammatory factors that may trigger the cutaneous immune system [5]. In this review, we will discuss recent developments in the genetic basis of skin barrier, immune phenotypes and the role of microbial pathogens in AD.

\section{Skin Barrier Defects in the Pathogenesis of AD}

The stratum corneum (SC) of the skin acts as an important barrier in preventing water loss from the skin as well as in protecting the skin from intrusion by irritants or microbes. Based mainly on trans-epidermal water loss (TEWL) studies, it has long been known that the SC of AD skin is defective. The TEWL in AD lesions is significantly greater, as compared to nonlesional AD skin as well as healthy skin [6,7]. In addition, it has been shown that nonlesional AD skin has greater TEWL as well as significantly thinner SC, as compared to healthy skin (12.2 microns vs. 19.7 microns) [reviewed in reference 8]. Increased TEWL correlates with increased AD severity [9]. Various proteins and lipids responsible for skin barrier function have been found to be deficient in $\mathrm{AD}$ skin. These molecules include filaggrin, involcrin, cholesterol, free fatty acids and ceramides [10,11]. More recently, a genetic basis for the skin barrier defect in AD has been demonstrated by the strong association between filaggrin gene mutations and $\mathrm{AD}$ [4]. 2 loss-of-function mutations in the filaggrin gene $(F L G)(\mathrm{R} 501 \mathrm{X}$ and 2282de14) have been linked to childhood-onset $\mathrm{AD}$, particularly in patients who have onset of AD 2 years or younger [12]. 21.3\% of patients with onset of AD 2 years or younger had one or more $F L G$ mutated alleles, as compared to $15.8 \%$ and $9.5 \%$ in patients with non- $F L G$ related childhood-onset AD and healthy controls, respectively [12]. These results were also replicated in AD patients with rarer FLG mutations: R2447X, S3247X, 3702delG and 3673delC [13]. In addition, it has been shown that patients with early-onset $\mathrm{AD}$ and $F L G$ mutations have a tendency to have persistent disease into adulthood [14]. FLG in AD patients was significantly associated with the extrinsic form of the disease (i.e. patients with elevated total serum $\operatorname{IgE}$ and/or presence of specific IgE against inhalant or food allergens), and the development of allergic rhinitis and asthma [15-19]. The association of IgE sensitization with $F L G$ in AD has recently been supported by a mouse model with homozygous frameshift mutation in filaggrin that is analogous to human $F L G$ [20]. This mouse model facilitates cutaneous allergen sensitization that leads to production of specific IgE. Although the association of $F L G$ with AD and atopy is clear, the role of $F L G$ in modifying immune response in human AD has not been established. Of note, approximately $40 \%$ of carriers of $F L G$ mutations showed no sign of $\mathrm{AD}$ [4]. Indeed, $F L G$ mutations were initially found to be the cause of ichthyosis vulgaris, which is a dry skin condition with no apparent inflammation or infection [21]. Therefore, additional factors must be involved in the pathogenesis of $\mathrm{AD}$.

\section{Susceptibility of AD Patients to Infections}

Psoriasis is another chronic skin disease with skin barrier defects. Based on TEWL experiments, psoriasis and $\mathrm{AD}$ were found to have similar physical barrier dysfunction [6]. However, $\mathrm{AD}$ is associated with recurrent bacterial or viral infection, whereas secondary infection in psoriasis is uncommon [22]. A deficiency in host defense molecules may contribute to the increased infections in AD. Sphingosine, a skin lipid with anti-S. aureus activity, has been shown to be significantly decreased in AD skin and lesions, as compared to healthy skin [23]. A decrease in dermcidin, an antimicrobial peptide (AMP) produced by eccrine sweat glands, has also been found to be decreased in AD [24]. 2 major classes of AMPs in cutaneous innate immunity, $\beta$-defensins and a cathelicidin (LL-37), have also been shown to be decreased in $\mathrm{AD}$, as compared to psoriasis [25,26]. In addition to a deficiency in the first-line defense against microbial pathogens, adaptive immunity may also play a role in perpetuating susceptibility of AD to infections. Cell wall components of S. aureus have 
been implicated as a trigger for the production of thymic stromal lymphopoietin (TSLP) by epithelial cells including keratinocytes [27]. This cytokine increases the production of Th2associated chemokines, CCL17 and CCL20, by macrophages or dendritic cells, leading to increased infiltration of Th2 cells, which express increased levels of Th2 cytokines, IL-4 and IL-13. These cytokines favor the attachment of $S$. aureus to in AD skin [28]. IL-4 and IL-13 also suppress filaggrin expression, contributing to further barrier compromise in AD [29]. In addition, IL-4 and IL-13 also suppress AMP expression by keratinocytes [25,26]. These 2 cytokines were shown to suppress the expression of human $\beta$ defensin-3 (HBD-3), a key beta-defensin against $S$. aureus, via the inhibition of mobilization of this AMP in keratinocyte, rather than via the suppression of gene expression [30]. IL-17 is a T cell cytokine that is capable of upregulating the expression of AMPs in keratinocytes [31]. Decreased IL-17 expression in AD lesions, as compared to that in psoriasis, may contribute to the reduced AMP expression in AD [32]. Th2 cytokines may further suppress IL-17 expression in keratinocytes [33], leading to lower expression of AMP in AD, as compared to that in psoriasis.

Environmental factors may also play a role in the increased colonization of $S$. aureus in AD. Patients with more severe AD have a higher level of $S$. aureus found in their home environment [34]. A mechanism for re-colonization of S. aureus in AD patients from the environment has been supported by studies that showed that AD patients and their close contacts have the same strains of $S$. aureus based on molecular techniques [35,36]. In addition, topical medications that are contaminated with $S$. aureus may become a source of bacterial re-colonization in AD patients [37].

\section{The Role of $S$. aureus in AD}

It is known that over $90 \%$ of $\mathrm{AD}$ patients are colonized with S. aureus, as compared to only $10 \%$ in the healthy individuals [38]. The severity of dermatitis correlates with the density of S. aureus colonization on AD skin lesions [39]. Anti-S. aureus antibiotics have been shown to improve the severity of AD [40]. These observations have provided support for the role of $S$. aureus in the pathogenesis of AD. Deficiency in AMP expression suggests an intrinsic defect in the innate immunity of AD [41]. S. aureus is detected by pattern recognition receptors in the innate immune system. Among the best-studied pattern recognition receptors are the toll-like receptors (TLR). TLR2 has been associated with the recognition of the cell wall components (lipoteichoic acid and possibly peptidoglycan) of gram positive bacteria including S. aureus [42]. Ahmad-Nejad et al. [43] showed that TLR2 polymorphism $\mathrm{R} 735 \mathrm{Q}$ is associated with a subgroup of patients with severe AD. Using human embryonic kidney 293 transfection system, they showed that this TLR2 polymorphism is associated with a significantly decreased expression of NF-אB, IP-10, and IL-8 [44]. TLR2-mediated production of IL-8 was shown to be significantly decreased in the monocytes of AD patients with TLR2 R735Q polymorphism [44]. On the other hand, the monocytes of these patients express significantly higher levels of IL-6 and IL-12, when compared to AD patients with wild type TLR2 [45]. Hasannejad et al [46] showed that TLR2-mediated production of IL-1 $\beta$ and TNF- $\alpha$ by monocytes was significantly diminished in AD patients. Dysregulation of cytokine production as a result of TLR defects may lead to inflammation in AD [45]. More recently, another TLR2 polymorphism A-16934T has also been associated with severe $\mathrm{AD}[47]$.

In addition to the cell wall components of $S$. aureus, alpha toxin from this bacteria is also capable of inducing immune dysregulation in AD. The prevalence of alpha toxin-producing S. aureus strains isolated from AD patients range from 30-60\% $[48,49]$, and the presence of alpha toxin-producing $S$. aureus is significantly associated with extrinsic AD [48]. Alpha toxin was found to induce profound keratinocyte cytotoxicity and lymphocyte apoptosis 
[49,50]. It also activates T cells to produce IFN- $\gamma$, leading to the development of chronic AD [49]. Other staphylococcal products that are frequently implicated in the pathogenesis of $A D$ are their enterotoxins (superantigens).

\section{The Role of Staphylococcal Superantigens in AD}

Superantigens are presented on the MHC II molecules of antigen-presenting cells to activate $\mathrm{T}$ cells. These antigens bind directly to the common variable $\beta(\mathrm{v} \beta)$ chains of $\mathrm{T}$ cell receptors, resulting in a polyclonal activation of T cells. Classic staphylococcal enterotoxins include staphylococcal enterotoxin (SE) A, SEB, SEC, SED and toxic shock syndrome toxin-1 (TSST-1). About 50\% of S. aureus isolated from AD patients secrete superantigens [51-53]. Direct application of superantigen on normal skin and unaffected AD skin induces erythema and causes flaring of skin disease in AD patients [54]. Increased AD severity correlates with the presence of superantigen-producing $S$. aureus $[53,55]$. Skin biopsy studies have shown the presence of $v \beta$ T cell clones corresponding to the specific superantigens in the $\mathrm{AD}$ lesions [52]. SEB has also been shown to induce lymphocyte expression of IL-31 [56], and this correlates with increased severity of AD [57]. A recent study that included both classical and non-classical staphylococcal superantigens (SEE and SEG-SEQ) showed that at least $80 \%$ of $S$. aureus isolated from AD patients are superantigen-producing [58]. Of these patients, a median number of 8 different superantigens were found per $S$. aureus isolate $[58,59]$. Patients with severe, corticosteroidinsensitive $\mathrm{AD}$ have been reported to harbor $S$. aureus strains that produce significantly higher number of superantigens per organism, as compared to that in a general population of AD patients [59]. These $S$. aureus strains that produce multiple superantigens, including SEB, SEC, TSST-1 and SEI-Q, are also associated with methicillin-resistant S. aureus (MRSA) [5], which may be a complicating factor in moderate to severe AD [60].

In addition to their ability to directly activate $\mathrm{T}$ cells, staphylococcal superantigens also induce the production of superantigen-specific IgE in AD patients [61]. Sensitization to superantigen-specific IgE has been correlated with the severity of $\mathrm{AD}$ [62]. The prevalence of superantigen-specific IgE in varying $\mathrm{AD}$ severity is as follows: $50-80 \%$ in severe $\mathrm{AD}$ [51,61], $60 \%$ in moderate $\mathrm{AD}$, and $40 \%$ in mild $\mathrm{AD}$ patients [64], as compared to none in healthy individuals [61]. Binding of superantigen-specific $\operatorname{IgE}$ with respective superantigen leads to the activation of basophils [61], which may play a crucial role in the initiation of IgE-mediated inflammation [64].

\section{The Role of Viral Skin Infections in AD}

$\mathrm{AD}$ patients are also susceptible to viral skin infection [22]. Eczema herpeticum (EH), which is caused by HSV, can present as a life-threatening infection. AD patients with disseminated EH present with fever, malaise and generalized vesicles [65]. EH patients may develop complications including keratoconjunctivitis, viremia, meningitis, encephalitits or secondary bacterial sepsis. Another life-threatening viral infection that may occur in AD is eczema vaccinatum $(E V)$, which is caused by vaccinia virus $(\mathrm{VV})$ in smallpox vaccine. Since the eradication of smallpox virus in the early seventies, routine vaccination with VV had been discontinued in the general population in 1972 and in military personnel in 1990. However, due to bioterrorism threats in recent years, a government program to vaccinate select military personnel and public health workers with smallpox vaccine has been reinstituted. Since then, one case of EV has been reported in the United States. An infant with AD contracted EV through his father who was in the military and had received smallpox vaccine 21 days prior to the onset of the infant's symptoms [66]. The infant needed life-saving measures including the use of investigational drugs via Emergency Investigational New Drug Application. The case illustrates the importance in understanding the mechanisms of 
$\mathrm{VV}$ infection in $\mathrm{AD}$ in order to identify AD patients at high risk for $\mathrm{EV}$ and to devise new treatments in $\mathrm{AD}$ patients with $\mathrm{EV}$. Due to the rarity of $\mathrm{EV}$ and its clinical resemblance to EH [66,67], understanding the mechanism of disease in EH has proven to be fruitful.

Beck et al. [68] in the National Institute of Allergy and Infectious Diseases-funded multicenter Atopic Dermatitis and Vaccinia Network (ADVN) study has recently shown that a subgroup of $\mathrm{AD}$ patients is particularly susceptible to $\mathrm{EH}$. This subgroup of $\mathrm{AD}$ patients have more severe disease, higher number of circulating eosinophils, higher levels of serum CCL17, more asthma and specific IgE sensitization to inhaled and food allergens, as compared to AD patients with no history of EH. Patients with history of EH are also more likely to have secondary skin infections with $S$. aureus. The clinical observation that patients with extrinsic $\mathrm{AD}$ are more susceptible to viral infection is consistent with laboratory findings that IL-4 and IL-13 suppress keratinocyte expression of the cathelicidin AMP, LL-37, which has potent anti-viral activity against HSV or VV [69,70]. Viral infections in $\mathrm{AD}$ further trigger the production of TSLP via TLR3, which increases the Th2 cytokine milieu in AD lesions, thereby leading to further susceptibility to disseminated viral infections [71]. IL-4 and IL-13 have also been found to suppress the expression of S100 calcium-binding protein A11 (S100A11) expression in keratinocytes [72]. Suppression of S100A11 expression leads to the down-regulation of IL-10R2, which is a receptor for IFN- $\lambda$, a cytokine with activity against VV [73].

Gao et al. [74] showed that a history of EH in AD patients was significantly associated with $F L G$ mutations. The frequency of R501X FLG was 3 times higher in AD patients with EH, as compared to those without EH. These findings were seen in both European and African Americans [74]. More recently, microarray analyses were applied to study VV-induced transcriptional changes in unaffected skin explants obtained from AD, psoriatic, and healthy individuals [75]. The skin samples were treated in vitro with vehicle or VV and subjected to gene ontology analysis. Wound healing and defense response genes were found to be among the most affected genes in $\mathrm{AD}$-specific responses to VV. Innate immunity genes including leukotriene B4 receptor (LTB4R), orosomucoid 1 (ORM1), coagulation factor II (thrombin) receptor (F2R), complement component 9 (C9), and lipopolysaccharide binding protein (LBP), were found to be significantly down-regulated in VV-treated AD explants, as compared to healthy individuals or psoriasis patients. These observations were confirmed with real-time (RT)-PCR. In addition, the down-regulation of innate immune response gene ORM1, TLR4, and NACHT leucine-rich repeat protein 1 (NLRP1) were found to be associated with AD severity. The latter two genes, TLR4 and NLRP1, are cell surface and intracellular pattern-recognition receptors, respectively, for microbial pathogens.

Compared to chronic $\mathrm{AD}$ lesions, acute $\mathrm{AD}$ lesions have been shown to have increased expression of IL-17 [76,77]. Patera et al. first noted that IL-17 increased the virulence of VV [78]. In an AD mouse model, increased IL-17 expression was found to be associated with filaggrin-deficient mice [79] and was responsible for the dissemination of VV in AD lesions [80]. This effect of IL-17 may be due to its suppression of NK activity against VV [81].

\section{The Role of Fungi}

The role of fungi in $\mathrm{AD}$ has been based primarily on observations of colonization by Malassezia species in AD patients. There has been controversy whether AD patients have increased colonization with Malassezia species, as compared to healthy controls. The controversy stems from differences in sampling methods, culture techniques and identification of different species. Using molecular techniques (nested and real-time RTPCR), Sugita et al. [82] found that Malassezia colonization is common in both AD patients and healthy subjects with detection rates of $100 \%$ and $78 \%$, respectively. Among the AD 
patients, they found that the head and neck areas are 7 and 10 times more likely to be colonized with Malassezia than the limb and trunk areas, respectively [83].

Baroni et al. [84] found that Malassezia (M.) furfur may induce AMP and IL-8 expression in keratinocytes via TLR-2. Selender, et al [85] found both TLR2-independent and - dependent pathways in the activation of mast cells by sympodialis. They showed that M. sympodialis induced the release of cysteinyl leukotrienes from non-IgE-sensitized mast cells. Using knock-out mice for TLR2 and MyD88, an adaptor molecule in most TLR pathways, they showed that IgE-sensitized mast cell degranulation and release of the chemokine MCP-1 was independent of TLR2 and MyD88, whereas IL-6 production was dependent on TLR2/ MyD88 pathway [85]. These findings are consistent with a recent study that showed the importance of a non-TLR pattern-recognition receptor, Mincle, in the recognition of Malassezia by the host immune system [86]. In that study, Malassezia was shown to activate inflammatory responses in macrophages via Mincle [86].

Malassezia species also induce the production of Malassezia-specific IgE in AD patients. These specific IgE sensitizations were found exclusively in AD patients, but not in patients with allergic rhinitis, urticaria or allergic contact dermatitis [87]. Malassezia-specific IgE molecules are significantly more prevalent in AD patients with head and neck dermatitis, as compared to AD patients with lesions in other locations (100 vs. 14\%)[88]. The prevalence and degree of IgE sensitization to Malassezia in $\mathrm{AD}$ patients are also age- and severitydependent. Adult AD patients were found to have a higher specific IgE levels to Malassezia, as compared to children with $\mathrm{AD}$ [89]. Among young children with $\mathrm{AD}$, the prevalence of IgE-sensitization to Malassezia were also significantly higher in the older age group than infants [90]. However, infants with severe AD and repeated oozing lesions are particularly at risk for developing specific IgE against Malassezia [91].

Malassezia may also contribute to AD inflammation via cell-mediated immunity and IgEmediated autoimmunity. Patients with intrinsic $\mathrm{AD}$ were also found to have a significantly higher prevalence of positive atopy patch tests to M. sympodialis, as compared to healthy controls (38 vs. 0\%)[87,92]. IgE-binding epitopes from M. sympodialis may cross-react with the human IgE autoantigen, manganese superoxide dismutase [93]. This may explain the ability of human manganese superoxide dismutase in inducing eczematous reactions in $M$. sympodialis-sensitized patients [94].

\section{The Role of Other Microbial Pathogens in AD}

Group A beta hemolytic Streptococcus can also cause skin infections in AD [95].

Streptococcal infection is associated with severe AD [96] and may result in complications including acute poststreptococcal glomerulonephritis, hypertension and posterior reversible encephalopathy syndrome [97]. Molluscum contagiosum (MC) virus belongs to the family of poxviruses. It causes skin lesions characterized by flesh-colored papules. AD patients are at increased risk for having higher number of MC lesions [98]. In addition, these lesions may lead to disfiguring scars in $\mathrm{AD}$ patients [99]. Patients with $\mathrm{EH}$ are also at increased risk for MC [68].

\section{Clinical Implications}

The discovery of FLG mutations as a predisposing factor for $\mathrm{AD}$ may lead to new molecular classification of eczema. Although it has been shown that $F L G$ facilitates the production of $\mathrm{IgE}$ in a mouse model of $F L G$ mutation, whether $F L G$ plays a role in modifying the immune response of $\mathrm{AD}$ in human remains to be proven. Further understanding of $F L G$ function may result in the development of targeted therapy in $\mathrm{AD}$ e.g. by increasing the expression of filaggrin [100]. Not only will this approach help AD patients with their skin disease, it may 
prevent the development of asthma in these patients since multiple studies have now confirmed the association of asthma with $F L G$ mutations in these patients. Genetic polymorphisms in the immune system remain an important area of research in the pathogenesis of $\mathrm{AD}$. Increasing evidence suggests that innate immunity is the primary driver of adaptive immunity. Genetic polymorphisms in TLR2, which is the chief extra-cellular pattern-recognition receptor for $S$. aureus, illustrates the potential role of innate immunity in defining the phenotypes of AD. These findings are crucial as $S$. aureus cell wall products have now been shown to be capable of enhancing the production of TSLP, a key molecule in subsequent Th2 immune responses, which include the production of IL-4 and IL-13. The roles of these two cytokines in AD have been well-characterized. They have been shown to suppress the expression of AMPs, filaggrin and S100A11, all of which contribute to the pathogenesis of AD. Therefore, IL-4 and IL-13 remain important targets in the therapy of $\mathrm{AD}$. The pathogenic roles of $S$. aureus in $\mathrm{AD}$ are numerous, including the production of superantigens, alpha toxin, stimulation of host TLR and superantigen-specific IgE. As chronic use of antibiotics leads to the development of resistant bacteria such as MRSA, which has an emerging role in $\mathrm{AD}$, new therapeutic approaches against $S$. aureus in $\mathrm{AD}$ are needed [1]. A recent study showed that bleach baths lead to significant improvement of AD in children although patients remain colonized by $S$. aureus [101]. Useful information on the role of viral infections in AD has been generated by ADVN studies. The identification of the subgroup of $\mathrm{AD}$ patients with increased susceptibility to $\mathrm{EH}$ i.e. those with more severe disease, early age of onset, increased $\mathrm{Th} 2$ response and allergic sensitization to common allergens, may help identify those AD patients who are at highest risk for EV. These observations may help clinicians in weighing the risks and benefits of smallpox vaccine in AD patients, in the event that the threat of bioterrorism with smallpox becomes imminent. Direct studies of VV infection in in vitro or mouse models have also helped to elucidate the mechanisms of VV infection in AD. The studies by Bin et al [74] and Grigoryev et al [75] provide further insight on the genes that are critical for the innate immune responses against $\mathrm{VV}$. These in turn may lead to novel approaches in treating or preventing VV infection in AD e.g. upregulation of S100A11, IL-10R2, ORM1, TLR4 or NLRP1 to increase innate immune response against VV. Increased expression of IL-17 in acute AD lesions may be an important predisposing factor in AD patients' susceptibility to VV. Thus, IL-17 may be a therapeutic target in limiting VV dissemination in AD patients. As Malassezia species play an important pathogenic role in a subgroup of AD patients, the identification of Mincle as the host pattern-recognition receptor for Malassezia may lead to novel therapies against this pathogen in $\mathrm{AD}$.

\section{References}

1. Boguniewicz M, Leung DYM. Recent insights into atopic dermatitis and implications for management of infectious complications. J Allergy Clin Immunol 2010;125:4-13. [PubMed: 20109729]

2. Benenson S, Zimhony O, Dahan D, et al. Atopic dermatitis--a risk factor for invasive Staphylococcus aureus infections: two cases and review. Am J Med 2005;118:10-1051. [PubMed: 16356802]

3. Wollenberg A, Wetzel S, Burgdorf WH, et al. Viral infections in atopic dermatitis: pathogenic aspects and clinical management. J Allergy Clin Immunol 2003;112(4):667-674. [PubMed: 14564342]

4. O'Regan GM, Sandilands A, McLean WH, et al. Filaggrin in atopic dermatitis. J Allergy Clin Immunol 2009;124(3 Suppl 2):R2-R6. [PubMed: 19720209]

5. Schlievert PM, Strandberg KL, Lin YC, et al. Secreted virulence factor comparison between methicillin-resistant and methicillin-sensitive Staphylococcus aureus, and its relevance to atopic dermatitis. J Allergy Clin Immunol 2010;125:39-49. [PubMed: 20109735] 
6. Grice K, Sattar H, Baker H, et al. The relationship of transepidermal water loss to skin temperature in psoriasis and eczema. J Invest Dermatol 1975;64(5):313-315. [PubMed: 1141706]

7. Seidenari S, Giusti G. Objective assessment of the skin of children affected by atopic dermatitis: a study of $\mathrm{pH}$, capacitance and TEWL in eczematous and clinically uninvolved skin. Acta Derm Venereol 1995;75(6):429-433. [PubMed: 8651017]

8. Cork MJ, Robinson DA, Vasilopoulos Y, et al. New perspectives on epidermal barrier dysfunction in atopic dermatitis: gene-environment interactions. J Allergy Clin Immunol 2006;118(1):3-21. [PubMed: 16815133]

9. Gupta J, Grube E, Ericksen MB, et al. Intrinsically defective skin barrier function in children with atopic dermatitis correlates with disease severity. J Allergy Clin Immunol 2008;121(3):725-730. [PubMed: 18249438]

10. Jensen JM, Fölster-Holst R, Baranowsky A, et al. Impaired sphingomyelinase activity and epidermal differentiation in atopic dermatitis. J Invest Dermatol 2004;122(6):1423-1431. [PubMed: 15175033]

11. Elias PM, Hatano Y, Williams ML. Basis for the barrier abnormality in atopic dermatitis: outsideinside-outside pathogenic mechanisms. J Allergy Clin Immunol 2008;121(6):1337-1343. [PubMed: 18329087]

12. Stemmler S, Parwez Q, Petrasch-Parwez E, et al. Two common loss-of-function mutations within the filaggrin gene predispose for early onset of atopic dermatitis. J Invest Dermatol 2007;127(3): 722-724. [PubMed: 17008875]

13. Brown SJ, Sandilands A, Zhao Y, et al. Prevalent and low-frequency null mutations in the filaggrin gene are associated with early-onset and persistent atopic eczema. J Invest Dermatol 2008;128(6): 1591-1594. [PubMed: 18094728]

14. Barker JN, Palmer CN, Zhao Y, et al. Null mutations in the filaggrin gene (FLG) determine major susceptibility to early-onset atopic dermatitis that persists into adulthood. J Invest Dermatol 2007;127(3):564-567. [PubMed: 16990802]

15. Weidinger S, Rodriguez E, Stahl C, et al. Filaggrin mutations strongly predispose to early-onset and extrinsic atopic dermatitis. J Invest Dermatol 2007;127(3):724-726. [PubMed: 17096018]

16. Weidinger S, Illig T, Baurecht $\mathrm{H}$, et al. Loss-of-function variations within the filaggrin gene predispose for atopic dermatitis with allergic sensitizations. J Allergy Clin Immunol 2006;118(1): 214-219. [PubMed: 16815158]

17. Marenholz I, Nickel R, Ruschendorf F, et al. Filaggrin loss-of-function mutations predispose to phenotypes involved in the atopic march. J Allergy Clin Immunol 2006;118(4):866-871. [PubMed: 17030239]

18. Henderson J, Northstone K, Lee SP, et al. The burden of disease associated with filaggrin mutations: a population-based, longitudinal birth cohort study. J Allergy Clin Immunol 2008;121(4):872-877. [PubMed: 18325573]

19. Rogers AJ, Celedon JC, Lasky-Su JA, et al. Filaggrin mutations confer susceptibility to atopic dermatitis but not to asthma. J Allergy Clin Immunol 2007;120(6):1332-1337. [PubMed: 18073125]

20. Fallon PG, Sasaki T, Sandilands A, et al. A homozygous frameshift mutation in the mouse Flg gene facilitates enhanced percutaneous allergen priming. Nat Genet 2009;41:602-608. [PubMed: 19349982]

21. Smith FJ, Irvine AD, Terron-Kwiatkowski A, et al. Loss-of-function mutations in the gene encoding filaggrin cause ichthyosis vulgaris. Nat Genet 2006;38(3):337-342. [PubMed: 16444271]

22. Christophers E, Henseler T. Contrasting disease patterns in psoriasis and atopic dermatitis. Arch Dermatol Res 1987;279 Suppl:S48-S51. [PubMed: 3662604]

23. Arikawa J, Ishibashi M, Kawashima M, et al. Decreased levels of sphingosine, a natural antimicrobial agent, may be associated with vulnerability of the stratum corneum from patients with atopic dermatitis to colonization by Staphylococcus aureus. J Invest Dermatol 2002;119(2): 433-439. [PubMed: 12190867] 
24. Rieg S, Steffen H, Seeber S, et al. Deficiency of dermcidin-derived antimicrobial peptides in sweat of patients with atopic dermatitis correlates with an impaired innate defense of human skin in vivo. J Immunol 2005;174(12):8003-8010. [PubMed: 15944307]

25. Ong PY, Ohtake T, Brandt C, et al. Endogenous antimicrobial peptides and skin infections in atopic dermatitis. N Engl J Med 2002;347:1151-1160. [PubMed: 12374875]

26. Nomura I, Goleva E, Howell MD, et al. Cytokine milieu of atopic dermatitis, as compared to psoriasis, skin prevents induction of innate immune response genes. J Immunol 2003;171:32623269. [PubMed: 12960356]

27. Allakhverdi Z, Comeau MR, Jessup HK, et al. Thymic stromal lymphopoietin is released by human epithelial cells in response to microbes, trauma, or inflammation and potently activates mast cells. J Exp Med 2007;204:253-258. [PubMed: 17242164]

28. Cho SH, Strickland I, Tomkinson A, et al. Preferential binding of Staphylococcus aureus to skin sites of Th2-mediated inflammmation in a murine model. J Invest Dermatol 2001;116:658-663. [PubMed: 11348452]

29. Howell MD, Kim BE, Gao P, et al. Cytokine modulation of atopic dermatitis filaggrin skin expression. J Allergy Clin Immunol 2009;124(3 Suppl 2):R7-R12. [PubMed: 19720210]

30. Kisich KO, Carspecken CW, Fiéve S, et al. Defective killing of Staphylococcus aureus in atopic dermatitis is associated with reduced mobilization of human beta-defensin-3. J Allergy Clin Immunol 2008;122(1):62-68. [PubMed: 18538383]

31. Liang SC, Tan XY, Luxenberg DP, et al. Interleukin (IL)-22 and IL-17 are coexpressed by Th17 cells and cooperatively enhance expression of antimicrobial peptides. J Exp Med 2006;203(10): 2271-2279. [PubMed: 16982811]

32. Guttman-Yassky E, Lowes MA, Fuentes-Duculan J, et al. Low expression of the IL-23/Th17 pathway in atopic dermatitis compared to psoriasis. J Immunol 2008;181(10):7420-7427. [PubMed: 18981165]

33. Eyerich K, Pennino D, Scarponi C, et al. IL-17 in atopic eczema: linking allergen-specific adaptive and microbial-triggered innate immune response. J Allergy Clin Immunol 2009;123(1):59-66. e4. [PubMed: 19056110]

34. Leung AD, Schiltz AM, Hall CF, et al. Severe atopic dermatitis is associated with a high burden of environmental Staphylococcus aureus. Clin Exp Allergy 2008;38(5):789-793. [PubMed: 18341620]

35. Bonness S, Szekat C, Novak N, et al. Pulsed-field gel electrophoresis of Staphylococcus aureus isolates from atopic patients revealing presence of similar strains in isolates from children and their parents. J Clin Microbiol 2008;46:456-461. [PubMed: 18077648]

36. Chiu LS, Ho MS, Hsu LY, et al. Prevalence and molecular characteristics of Staphylococcus aureus isolates colonizing patients with atopic dermatitis and their close contacts in Singapore. $\mathrm{Br}$ J Dermatol 2009;160(5):965-971. [PubMed: 19222456]

37. Gilani SJ, Gonzalez M, Hussain I, et al. Staphylococcus aureus re-colonization in atopic dermatitis: beyond the skin. Clin Exp Dermatol 2005;30:10-13. [PubMed: 15663492]

38. Leyden JJ, Marples RR, Kligman AM. Staphylococcal aureus in the lesions of atopic dermatitis. Br J Dermatol 1974;90:525-530. [PubMed: 4601016]

39. Williams RE, Gibson AG, Aitchison TC, et al. Assessment of a contact-plate sampling technique and subsequent quantitative bacterial studies in atopic dermatitis. Br J Dermatol 1990;123(4):493501. [PubMed: 2095181]

40. Breuer K, HAussler S, Kapp A, et al. Staphylococcus aureus: colonizing features and influence of an antibacterial treatment in adults with atopic dermatitis. Br J Dermatol 2002;147(1):55-61. [PubMed: 12100185]

41. Ong PY. Is/are pattern recognition receptor(s) for Staphylococcus aureus defective in atopic dermatitis? Dermatology 2006;212(1):19-22. [PubMed: 16319468]

42. Fournier B, Philpott DJ. Recognition of Staphylococcus aureus by the innate immune system. Clin Microbiol Rev 2005;18(3):521-540. [PubMed: 16020688]

43. Ahmad-Nejad P, Mrabet-Dahbi S, Breuer K, et al. The toll-like receptor 2 R753Q polymorphism defines a subgroup of patients with atopic dermatitis having severe phenotype. J Allergy Clin Immunol 2004;113:565-567. [PubMed: 15007364] 
44. Mrabet-Dahbi S, Dalpke AH, Niebuhr M, et al. The Toll-like receptor 2 R753Q mutation modifies cytokine production and Toll-like receptor expression in atopic dermatitis. J Allergy Clin Immunol 2008;121(4):1013-1019. [PubMed: 18234309]

45. Niebuhr M, Langnickel J, Draing C, et al. Dysregulation of toll-like receptor-2 (TLR-2)-induced effects in monocytes from patients with atopic dermatitis: impact of the TLR-2 R753Q polymorphism. Allergy 2008;63(6):728-734. [PubMed: 18445187]

46. Hasannejad H, Takahashi R, Kimishima M, et al. Selective impairment of Toll-like receptor 2mediated proinflammatory cytokine production by monocytes from patients with atopic dermatitis. J Allergy Clin Immunol 2007;120(1):69-75. [PubMed: 17531301]

47. Oh DY, Schumann RR, Hamann L, et al. Association of the toll-like receptor 2 A-16934T promoter polymorphism with severe atopic dermatitis. Allergy 2009;64(11):1608-1615. [PubMed: 19627277]

48. Wichmann K, Uter W, Weiss J, et al. Isolation of alpha-toxin-producing Staphylococcus aureus from the skin of highly sensitized adult patients with severe atopic dermatitis. Br J Dermatol 2009;161(2):300-305. [PubMed: 19438853]

49. Breuer K, Wittmann M, Kempe K, et al. Alpha-toxin is produced by skin colonizing Staphylococcus aureus and induces a T helper type 1 response in atopic dermatitis. Clin Exp Allergy 2005;35:1088-1095. [PubMed: 16120092]

50. Ezepchuk YV, Leung DYM, Middleton MH, et al. Staphylococcal toxins and protein A differentially induce cytotoxicity and release of tumor necrosis factor-alpha from human keratinocytes. J Invest Dermatol 1996;107:603-609. [PubMed: 8823368]

51. Nomura I, Tanaka K, Tomita H, et al. Evaluation of the staphylococcal exotoxins and their specific IgE in childhood atopic dermatitis. J Allergy Clin Immunol 1999;104:441-446. [PubMed: 10452768]

52. Bunikowski R, Mielke ME, Skarabis H, et al. Evidence for a disease-promoting effect of Staphylococcus aureus-derived exotoxins in atopic dermatitis. J Allergy Clin Immunol 2000;105:814-819. [PubMed: 10756234]

53. Tomi NS, Kranke B, Aberer E. Staphylococcal toxins in patients with psoriasis, atopic dermatitis, and erythroderma, and in healthy control subjects. J Am Acad Dermatol 2005;53:67-72. [PubMed: 15965423]

54. Strange P, Skov L, Lisby S, et al. Staphylococcal enterotoxin B applied on intact normal and intact atopic skin induces dermatitis. Arch Dermatol 1996;132(1):27-33. [PubMed: 8546480]

55. Zollner TM, Wichelhaus TA, Hartung A, et al. Colonization with superantigen-producing Staphylococcus aureus is associated with increased severity of atopic dermatitis. Clin Exp Allergy 2000;30:994-1000. [PubMed: 10848922]

56. Sonkoly E, Muller A, Lauerma AI, et al. IL-31: a new link between T cells and pruritus in atopic skin inflammation. J Allergy Clin Immunol 2006;117(2):411-417. [PubMed: 16461142]

57. Raap U, Wichmann K, Bruder M, et al. Correlation of IL-31 serum levels with severity of atopic dermatitis. J Allergy Clin Immunol 2008;122(2):421-423. [PubMed: 18678344]

58. Leung DY, Hanifin JM, Pariser DM, et al. Effects of pimecrolimus cream $1 \%$ in the treatment of patients with atopic dermatitis who demonstrate a clinical insensitivity to topical corticosteroids: a randomized, multicentre vehicle-controlled trial. Br J Dermatol 2009;161(2):435-443. [PubMed: 19416245]

59. Schlievert PM, Case LC, Strandberg KL, et al. Superantigen profile of Staphylococcus aureus isolates from patients with steroid-resistant atopic dermatitis. Clin Infect Dis 2008;46:1562-1567. [PubMed: 18419342]

60. Hon KL, Leung AK, Kong AY, et al. Atopic dermatitis complicated by methicillin-resistant Staphylococcus aureus infection. J Natl Med Assoc 2008;100(7):797-800. [PubMed: 18672556]

61. Leung DYM, Harbeck R, Bina P, et al. Presence of IgE antibodies to staphylococcal exotoxins on the skin of patients with atopic dermatitis. Evidence for a new group of allergens. J Clin Invest 1993;92:1374-1380. [PubMed: 7690780]

62. Bunikowski R, Mielke M, Skarabis H, et al. Prevalence and role of serum IgE antibodies to the Staphylococcus aureus-derived superantigens SEA and SEB in children with atopic dermatitis. J Allergy Clin Immunol 1999;103(1 Pt 1):119-124. [PubMed: 9893195] 
63. Ong PY, Patel M, Ferdman RM, et al. Association of staphylococcal superantigen-specific immunoglobulin e with mild and moderate atopic dermatitis. J Pediatr 2008;153(6):803-806. [PubMed: 18621391]

64. Karasuyama H, Mukai K, Tsujimura Y, et al. Newly discovered roles for basophils: a neglected minority gains new respect. Nat Rev Immunol 2009;9(1):9-13. [PubMed: 19039320]

65. Wollenberg A, Wetzel S, Burgdorf WH, et al. Viral infections in atopic dermatitis: pathogenic aspects and clinical management. J Allergy Clin Immunol 2003;112(4):667-674. [PubMed: 14564342]

66. Vora S, Damon I, Fulginiti V, et al. Severe eczema vaccinatum in a household contact of a smallpox vaccinee. Clin Infect Dis 2008;46(10):1555-1561. [PubMed: 18419490]

67. Boyd DA, Sperling LC, Norton SA. Eczema herpeticum and clinical criteria for investigating smallpox. Emerg Infect Dis 2009;15(7):1102-1104. [PubMed: 19624930]

68. Beck LA, Boguniewicz M, Hata T, et al. Phenotype of atopic dermatitis subjects with a history of eczema herpeticum. J Allergy Clin Immunol 2009;124(2):260-269. [PubMed: 19541356]

69. Howell MD, Wollenberg A, Gallo RL, et al. Cathelicidin deficiency predisposes to eczema herpeticum. J Allergy Clin Immunol 2006;117(4):836-841. [PubMed: 16630942]

70. Howell MD, Gallo RL, Boguniewicz M, et al. Cytokine milieu of atopic dermatitis skin subverts the innate immune response to vaccinia virus. Immunity 2006;24(3):341-348. [PubMed: 16546102]

71. Kinoshita H, Takai T, Le TA, et al. Cytokine milieu modulates release of thymic stromal lymphopoietin from human keratinocytes stimulated with double-stranded RNA. J Allergy Clin Immunol 2009;123(1):179-186. [PubMed: 19056108]

72. Howell MD, Fairchild HR, Kim BE, et al. Th2 cytokines act on S100/A11 to downregulate keratinocyte differentiation. J Invest Dermatol 2008;128(9):2248-2258. [PubMed: 18385759]

73. Bin L, Howell MD, Kim BE, et al. Inhibition of S100A11 gene expression impairs keratinocyte response against vaccinia virus through downregulation of the IL-10 receptor 2 chain. J Allergy Clin Immunol 2009;124(2):270-277. [PubMed: 19577285]

74. Gao PS, Rafaels NM, Hand T, et al. Filaggrin mutations that confer risk of atopic dermatitis confer greater risk for eczema herpeticum. J Allergy Clin Immunol 2009;124(3):507-513. [PubMed: 19733298]

75. Grigoryev DN, Howell MD, Watkins TN, et al. Vaccinia virus-specific molecular signature in atopic dermatitis skin. J Allergy Clin Immunol 2010;125:153-159. e28. [PubMed: 20109744]

76. Toda M, Leung DY, Molet S, et al. Polarized in vivo expression of IL-11 and IL-17 between acute and chronic skin lesions. J Allergy Clin Immunol 2003;111(4):875-881. [PubMed: 12704372]

77. Koga C, Kabashima K, Shiraishi N, et al. Possible pathogenic role of Th17 cells for atopic dermatitis. J Invest Dermatol 2008;128(11):2625-2630. [PubMed: 18432274]

78. Patera AC, Pesnicak L, Bertin J, et al. Interleukin 17 modulates the immune response to vaccinia virus infection. Virology 2002;299(1):56-63. [PubMed: 12167341]

79. Oyoshi MK, Murphy GF, Geha RS. Filaggrin-deficient mice exhibit TH17-dominated skin inflammation and permissiveness to epicutaneous sensitization with protein antigen. J Allergy Clin Immunol 2009;124(3):485-493. [PubMed: 19665780]

80. Oyoshi MK, Elkhal A, Kumar L, et al. Vaccinia virus inoculation in sites of allergic skin inflammation elicits a vigorous cutaneous IL-17 response. Proc Natl Acad Sci U S A 2009;106(35):14954-14959. [PubMed: 19706451]

81. Kawakami Y, Tomimori Y, Yumoto K, et al. Inhibition of NK cell activity by IL-17 allows vaccinia virus to induce severe skin lesions in a mouse model of eczema vaccinatum. J Exp Med 2009;206(6):1219-1225. [PubMed: 19468065]

82. Sugita T, Suto H, Unno T, et al. Molecular analysis of Malassezia microflora on the skin of atopic dermatitis patients and healthy subjects. J Clin Microbiol 2001;39(10):3486-3490. [PubMed: 11574560]

83. Sugita T, Tajima M, Tsubuku H, et al. Quantitative analysis of cutaneous malassezia in atopic dermatitis patients using real-time PCR. Microbiol Immunol 2006;50(7):549-552. [PubMed: 16858146] 
84. Baroni A, Orlando M, Donnarumma G, et al. Toll-like receptor 2 (TLR2) mediates intracellular signalling in human keratinocytes in response to Malassezia furfur. Arch Dermatol Res 2006;297(7):280-288. [PubMed: 16283346]

85. Selander C, Engblom C, Nilsson G, et al. TLR2/MyD88-dependent and -independent activation of mast cell IgE responses by the skin commensal yeast Malassezia sympodialis. J Immunol 2009;182(7):4208-4216. [PubMed: 19299719]

86. Yamasaki S, Matsumoto M, Takeuchi O, et al. C-type lectin Mincle is an activating receptor for pathogenic fungus, Malassezia. Proc Natl Acad Sci U S A 2009;106(6):1897-1902. [PubMed: 19171887]

87. Casagrande BF, Flückiger S, Linder MT, et al. Sensitization to the yeast Malassezia sympodialis is specific for extrinsic and intrinsic atopic eczema. J Invest Dermatol 2006;126(11):2414-2421. [PubMed: 16778796]

88. Devos SA, van der Valk PG. The relevance of skin prick tests for Pityrosporum ovale in patients with head and neck dermatitis. Allergy 2000;55(11):1056-1058. [PubMed: 11097316]

89. Takahata Y, Sugita T, Kato H, et al. Cutaneous Malassezia flora in atopic dermatitis differs between adults and children. Br J Dermatol 2007;157(6):1178-1182. [PubMed: 17916215]

90. Ong PY, Ferdman RM, Church JA. Late-onset of IgE sensitization to microbial allergens in young children with atopic dermatitis. Br J Dermatol. 2009 Sept 8; [E pub ahead of print].

91. Lange L, Alter N, Keller T, et al. Sensitization to Malassezia in infants and children with atopic dermatitis: prevalence and clinical characteristics. Allergy 2008;63(4):486-487. [PubMed: 18315742]

92. Johansson C, Sandström MH, Bartosik J, et al. Atopy patch test reactions to Malassezia allergens differentiate subgroups of atopic dermatitis patients. Br J Dermatol 2003;148(3):479-488. [PubMed: 12653739]

93. Vilhelmsson M, Glaser AG, Martinez DB, et al. Mutational analysis of amino acid residues involved in IgE-binding to the Malassezia sympodialis allergen Mala s 11. Mol Immunol 2008;46(2):294-303. [PubMed: 18922581]

94. Schmid-Grendelmeier P, Flückiger S, Disch R, et al. IgE-mediated and T cell-mediated autoimmunity against manganese superoxide dismutase in atopic dermatitis. J Allergy Clin Immunol 2005;115(5):1068-1075. [PubMed: 15867868]

95. Brook I, Frazier EH, Yeager JK. Microbiology of infected atopic dermatitis. Int J Dermatol 1996;35(11):791-793. [PubMed: 8915731]

96. Hayakawa K, Hirahara K, Fukuda T, et al. Risk factors for severe impetiginized atopic dermatitis in Japan and assessment of its microbiological features. Clin Exp Dermatol 2009;34(5):e63-e65. [PubMed: 19438578]

97. Park JM, Oh SH, Kim J, et al. Atopic dermatitis with group A beta-hemolytic Streptococcus skin infection complicated by posterior reversible encephalopathy syndrome. Arch Dermatol 2009;145(7):846-847. [PubMed: 19620577]

98. Dohil MA, Lin P, Lee J, et al. The epidemiology of molluscum contagiosum in children. J Am Acad Dermatol 2006;54(1):47-54. [PubMed: 16384754]

99. Ghura HS, Camp RD. Scarring molluscum contagiosum in patients with severe atopic dermatitis: report of two cases. Br J Dermatol 2001;144(5):1094-1095. [PubMed: 11359410]

100. Sandilands A, Sutherland C, Irvine AD, et al. Filaggrin in the frontline: role in skin barrier function and disease. J Cell Sci 2009;122(Pt 9):1285-1294. [PubMed: 19386895]

101. Huang JT, Abrams M, Tlougan B, et al. Treatment of Staphylococcus aureus colonization in atopic dermatitis decreases disease severity. Pediatrics 2009;123(5):e808-e814. [PubMed: 19403473] 
Table 1

Recent developments in the infectious aspects of atopic dermatitis

1 Filaggrin gene mutations facilitate IgE expression in a mouse model [ref. 20].

2 Toll-like receptor genetic polymorphisms may lead to cytokine dysregulation and inflammation in AD [refs. 45,46,47].

3 Emerging roles of non-classical staphylococcal superantigens (SEE and SEG-SEQ) and methicillin-resistant $S$. aureus in the pathogenesis of $\mathrm{AD}$ [refs. 5,58,59].

4 AD patients with specific IgE sensitization or other atopic diseases including asthma and food allergy are at increased risk for viral skin infections [ref. 68].

5 Innate immune response genes including leukotriene B4 receptor (LTB4R), orosomucoid 1 (ORM1), coagulation factor II (thrombin) receptor (F2R), complement component 9 (C9), lipopolysaccharide binding protein (LBP), and leucine-rich repeat protein 1 (NLRP1) may be involved in the pathogenesis of vaccinia virus infection in AD [ref. 75]) 